Supporting Information

\title{
Differences in the Nature of Active Sites for Methane Dry Reforming and Methane Steam Reforming over Nickel Aluminate \\ Catalysts
}

Jessica L. Rogers ${ }^{1,2,3}$, Michael C. Mangarella ${ }^{1}$, Andrew D. D'Amico ${ }^{4}$, James R. Gallagher ${ }^{5}$, Michael R. Dutzer ${ }^{1,2}$, Eli Stavitski ${ }^{6}$, Jeffrey T. Miller ${ }^{5,7}$, Carsten Sievers $^{1,2^{*}}$

${ }^{1}$ School of Chemical \& Biomolecular Engineering, Georgia Institute of Technology, Atlanta, GA 30332, U.S.A.

${ }^{2}$ Renewable Bioproducts Institute, Georgia Institute of Technology, Atlanta, GA 30332, U.S.A.

${ }^{3}$ The Dow Chemical Company, Freeport, TX 77541, U.S.A.

${ }^{4}$ Micromeritics Instrument Corporation, Norcross, GA 30093, U.S.A.

${ }^{5}$ Argonne National Laboratory, Chemical Technology Division, Argonne, IL 60430, U.S.A.

${ }^{6}$ National Synchrotron Light Source II, Brookhaven National Laboratory, Upton, NY 11973, U.S.A.

${ }^{7}$ School of Chemical Engineering, Purdue University, W. Lafayette, IN 47907, U.S.A.

* Phone: +1-404-385-7685, Fax:+1-404-894-2866, Email: carsten.sievers@chbe.gatech.edu 


\section{Calculations}

$$
\begin{aligned}
& X_{C_{4}}(\%)=\frac{N_{C_{4} H_{I N}}-N_{C H_{4} \text { OUT }}}{N_{C H_{4 I N}}} * 100 \\
& X_{\mathrm{CO}_{2}}(\%)=\frac{N_{\mathrm{CO}_{2 I N}}-N_{\mathrm{CO}_{2} \mathrm{OUT}}}{N_{\mathrm{CO}_{2}{ }_{I N}}} * 100 \\
& \text { Yield }_{H_{2}}(\%)=\frac{N_{H_{2 F O R M E D}}}{2 * N_{C H_{4 I N}}} * 100 \\
& \text { Yield }_{C O}(\%)=\frac{N_{C O_{F O R M E D}}}{2 * N_{C H_{4 I N}}} * 100
\end{aligned}
$$




\section{Additional Figures}

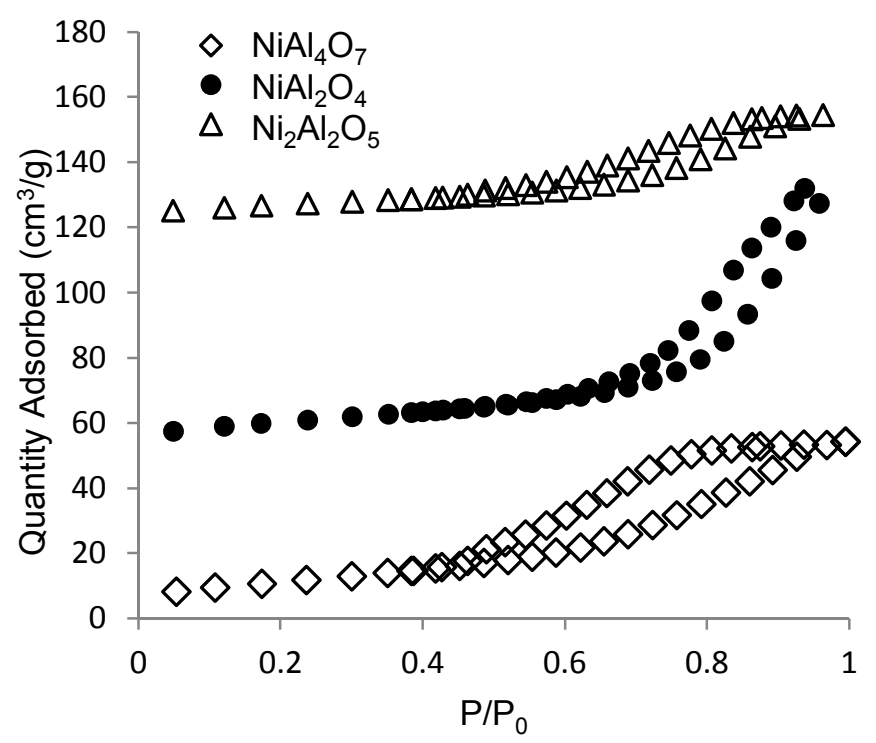

Figure $\mathrm{S} 1-\mathrm{N}_{2}$ physisorption adsorption/desorption isotherms for nickel aluminates. $\mathrm{NiAl}_{2} \mathrm{O}_{4}$ and $\mathrm{Ni}_{2} \mathrm{Al}_{2} \mathrm{O}_{5}$ offset by 50 and $120 \mathrm{~cm}^{3} / \mathrm{g}$, respectively, for clarity. 


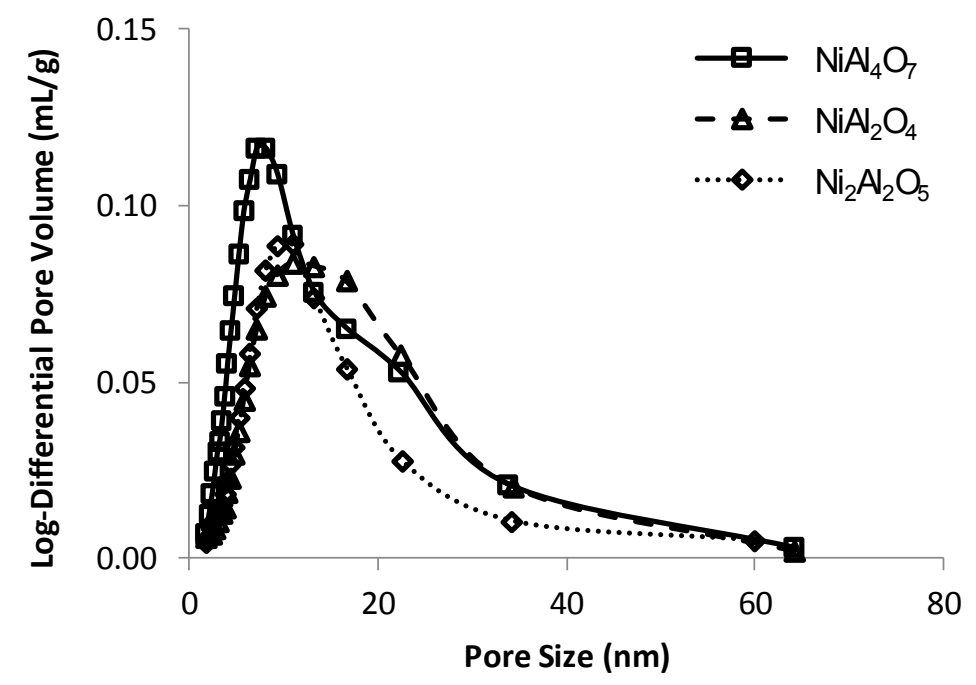

Figure $\mathrm{S} 2-\mathrm{BJH}$ pore size distribution based on $\mathrm{N}_{2}$ physisorption adsorption/desorption isotherms for nickel aluminates.

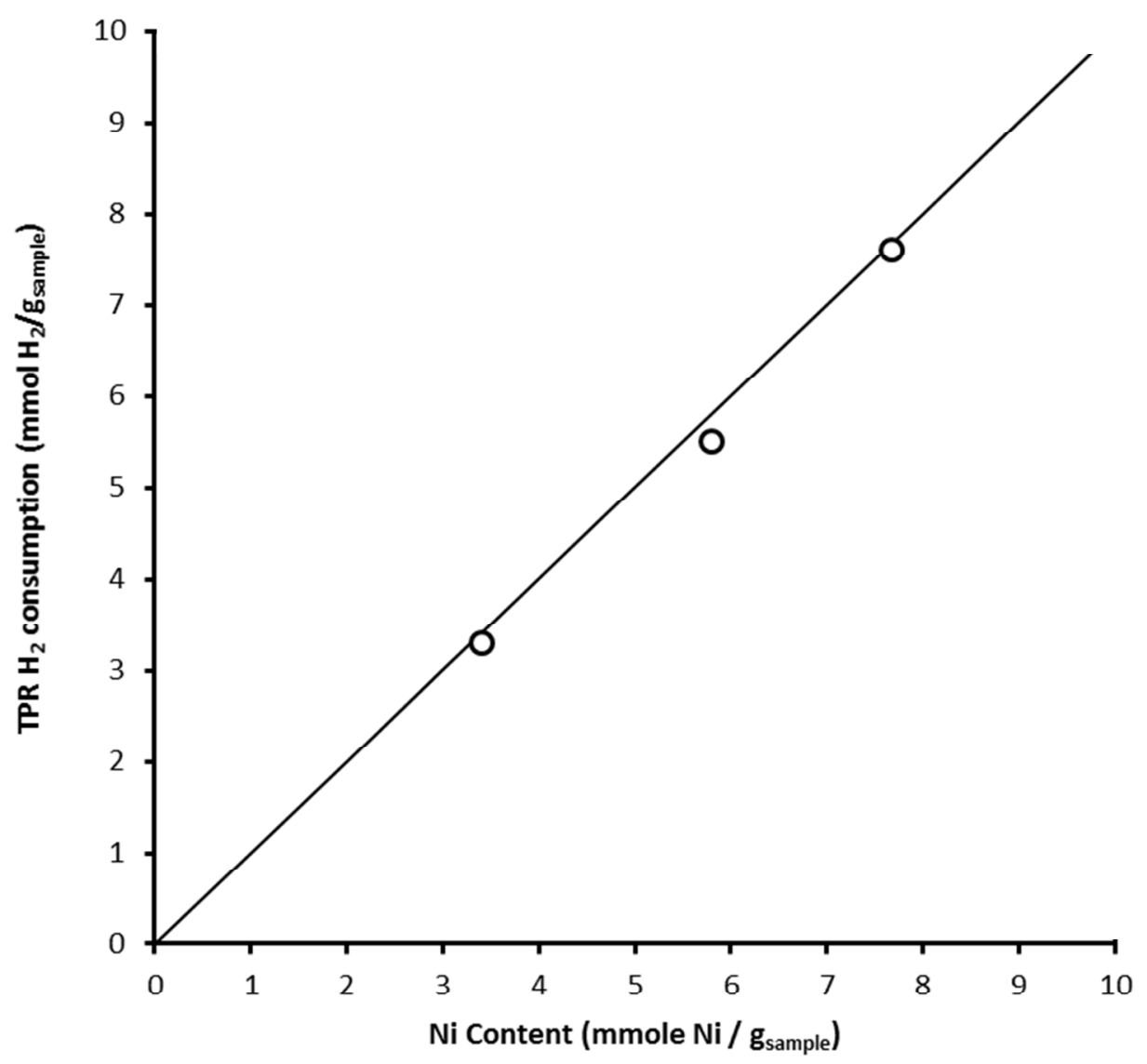

Figure $\mathrm{S} 3-\mathrm{H}_{2}$ consumption during TPR as a function of $\mathrm{Ni}$ content of the sample. 


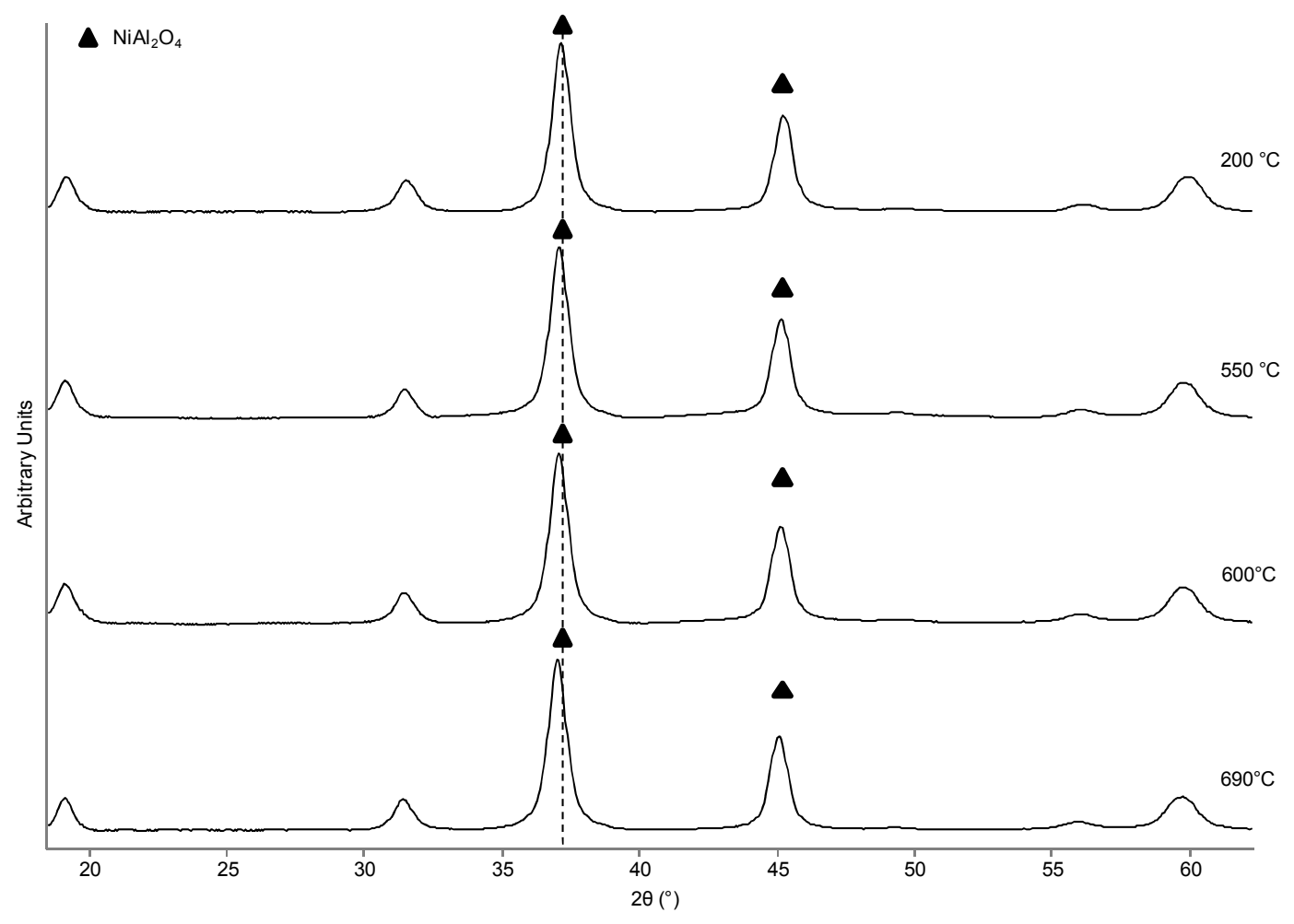

Figure $\mathrm{S} 4$ - X-ray diffractograms of $\mathrm{NiAl}_{4} \mathrm{O}_{7}$ exposed to hydrogen as a function of increasing temperature. 


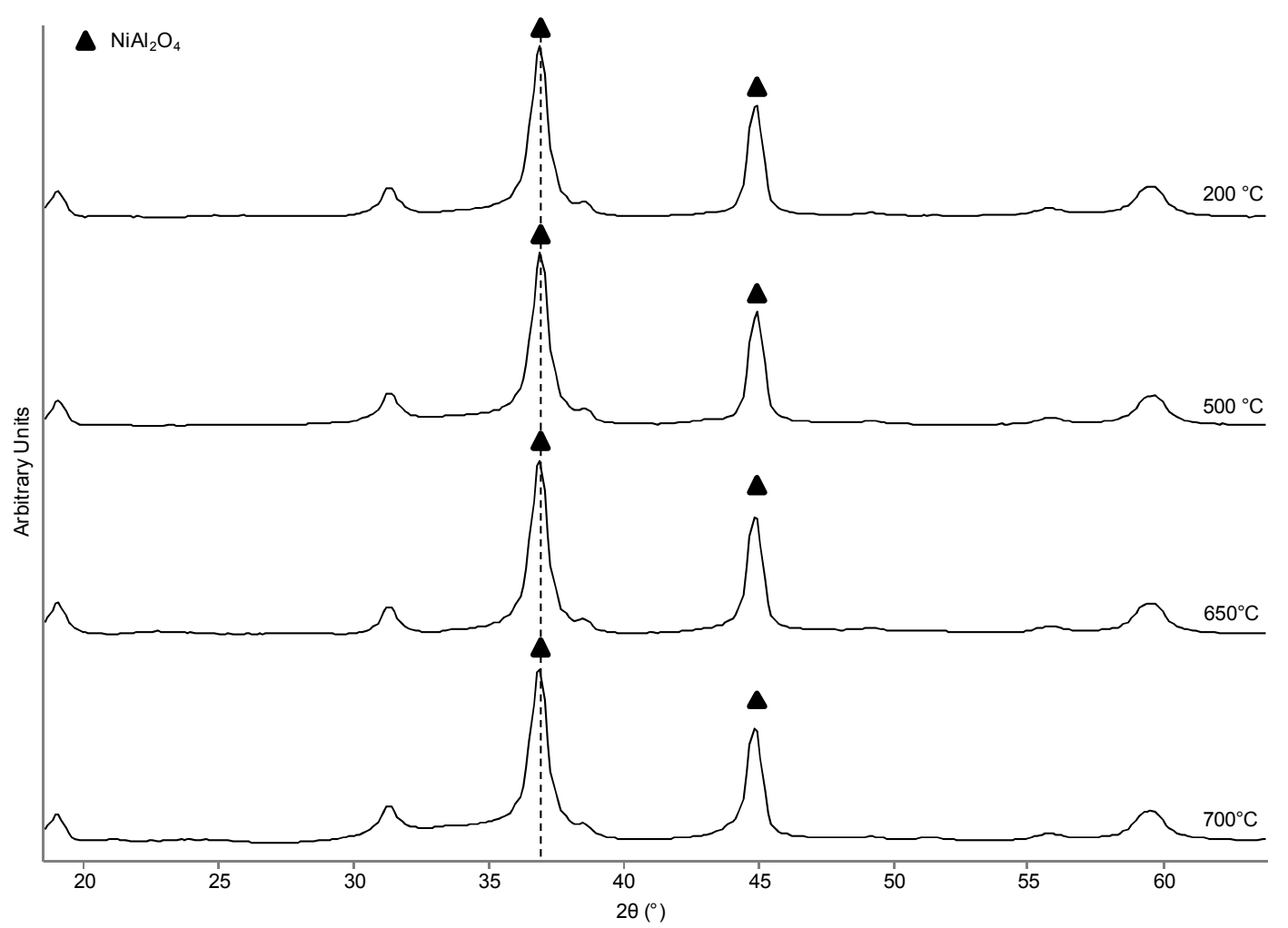

Figure S5 - X-ray diffractograms of $\mathrm{NiAl}_{2} \mathrm{O}_{4}$ exposed to hydrogen as a function of increasing temperature. 


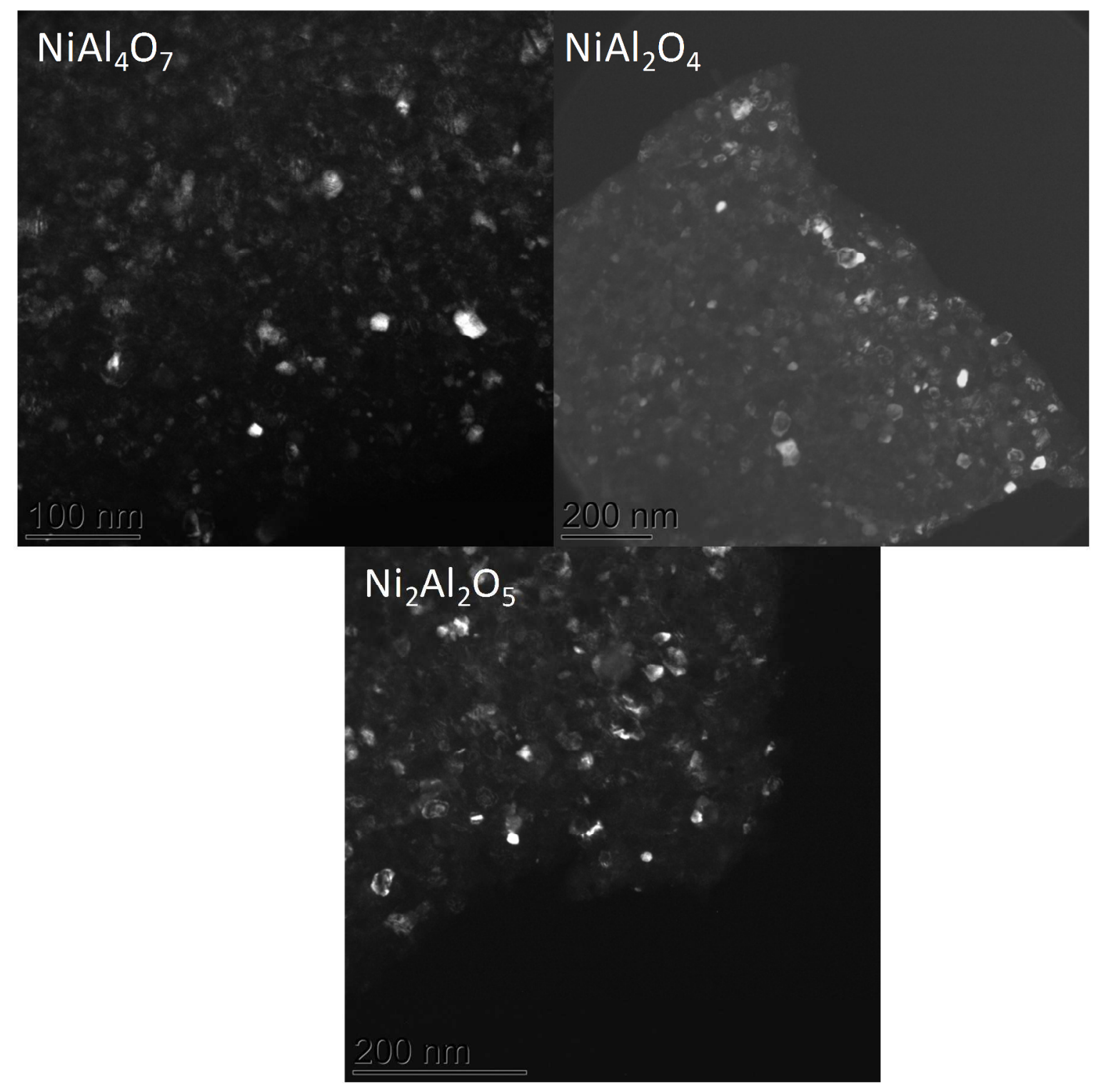

Figure S6 - Dark field TEM images used to calculate grain sizes of nickel aluminates. 

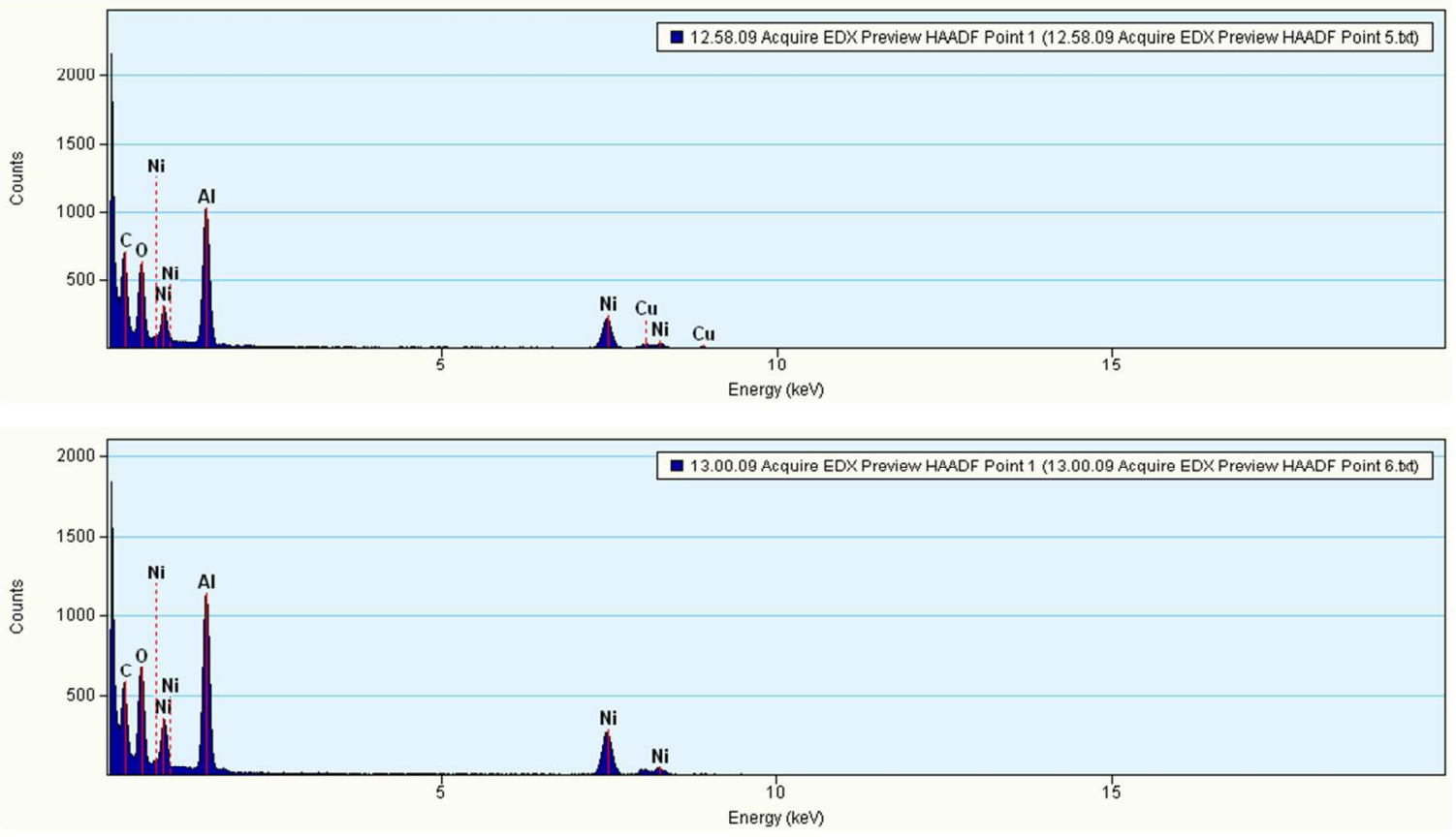

Figure $\mathrm{S} 7$ - HAADF-STEM-EDX of $\mathrm{NiAl}_{4} \mathrm{O}_{7}$. 

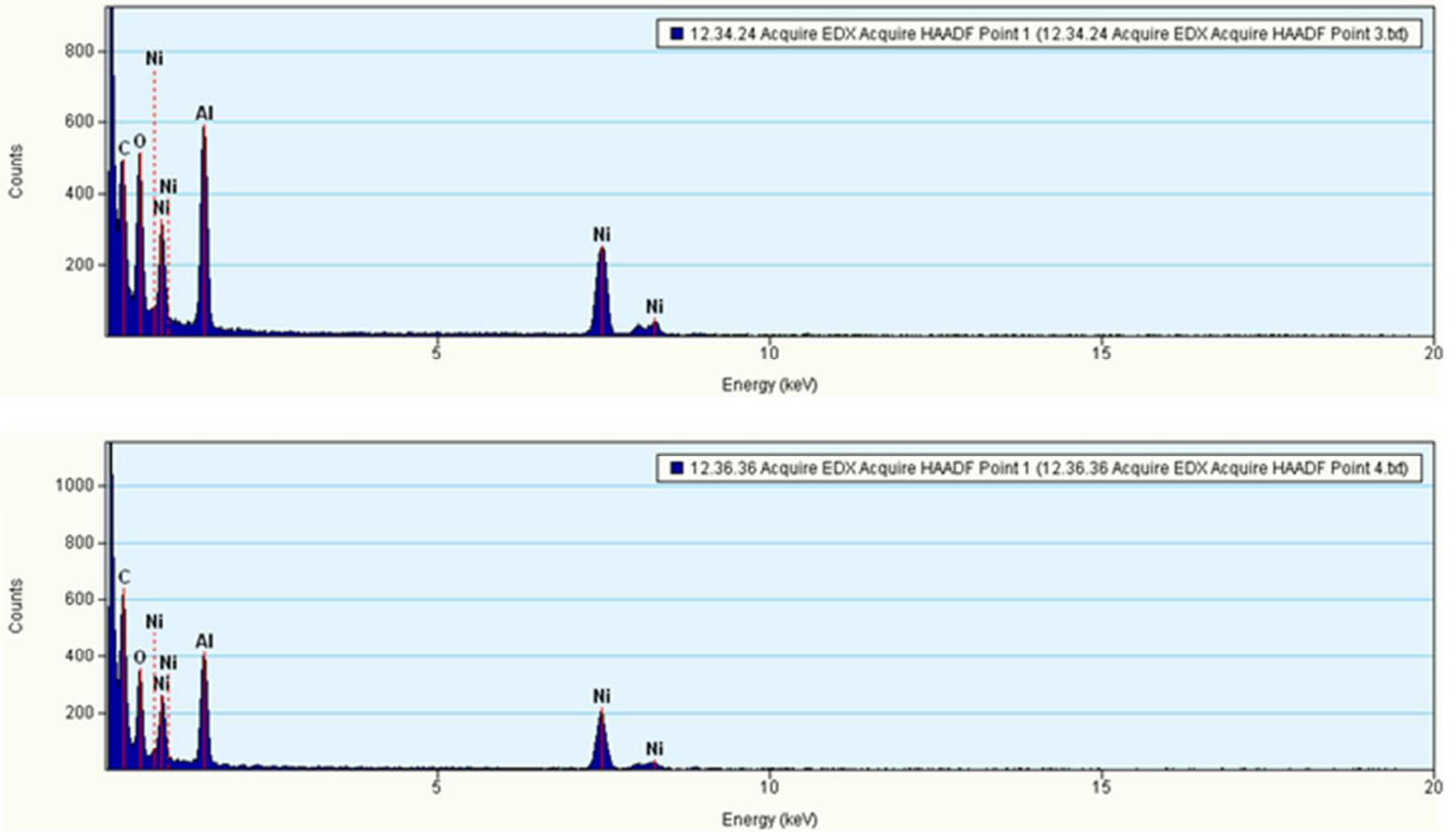

Figure $\mathrm{S} 8$ - HAADF-STEM-EDX of $\mathrm{NiAl}_{2} \mathrm{O}_{4}$.
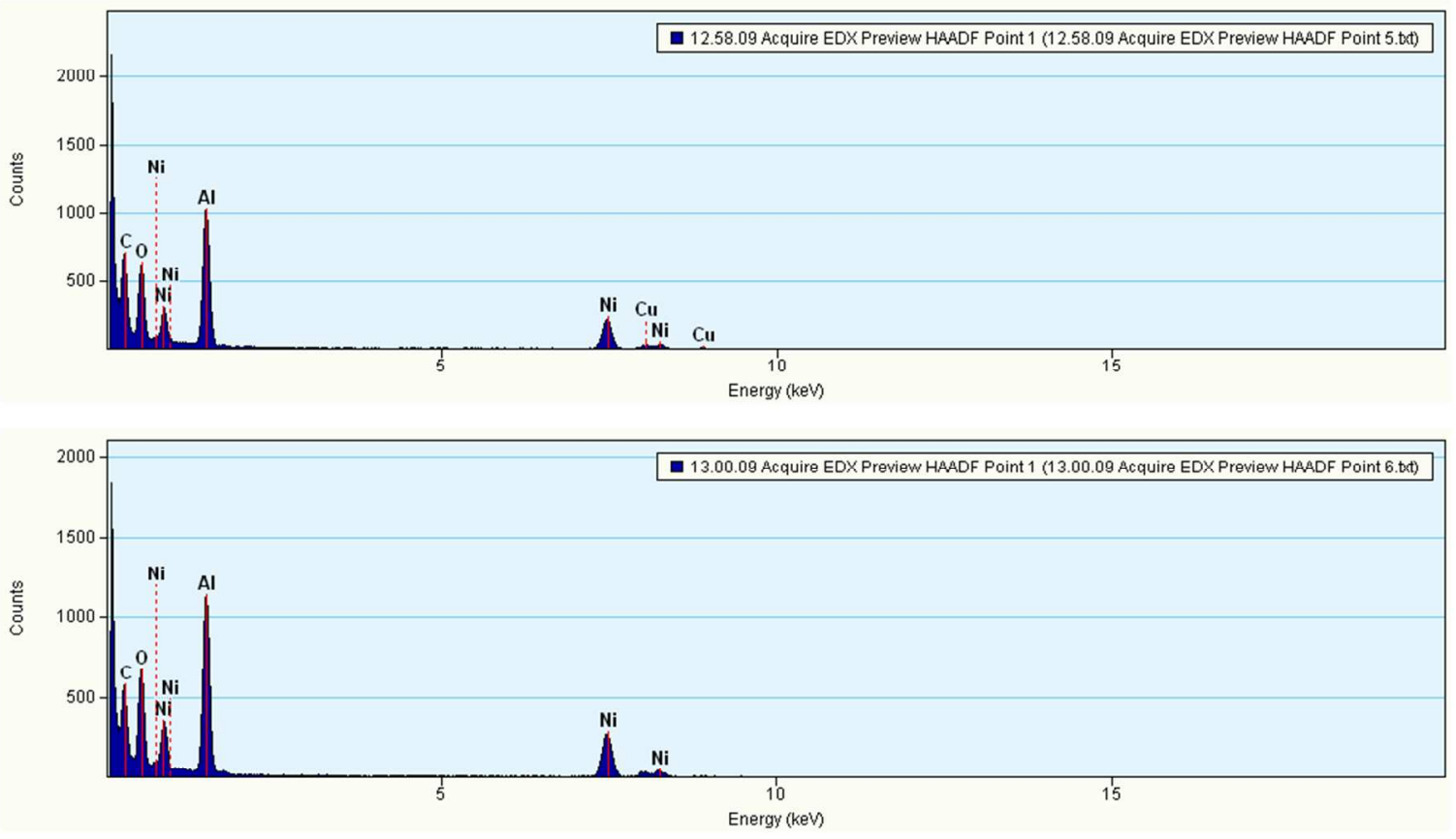

Figure $\mathrm{S} 9$ - HAADF-STEM-EDX of $\mathrm{Ni}_{2} \mathrm{Al}_{2} \mathrm{O}_{5}$. 


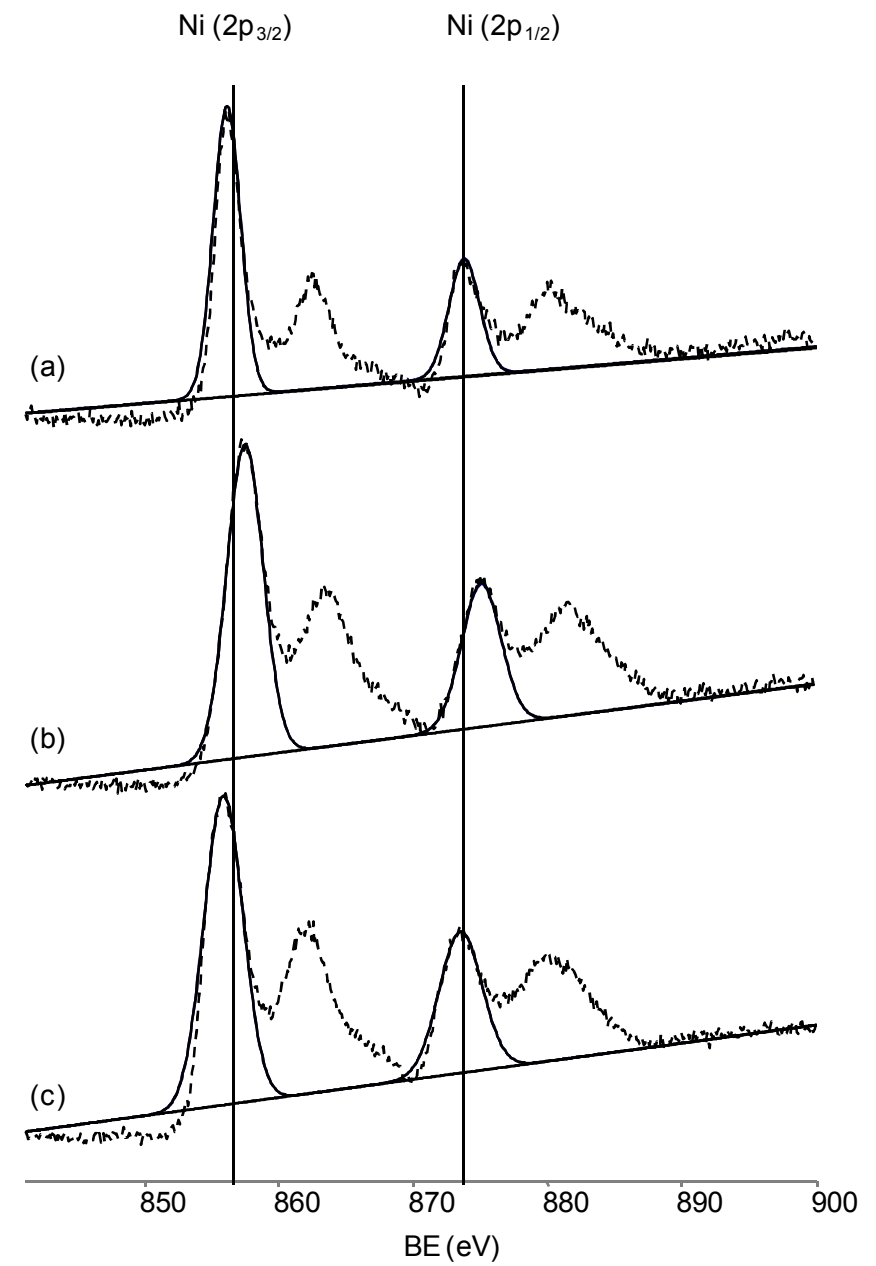

Figure $\mathrm{S} 10$ - Ni 2p XPS of (a) $\mathrm{NiAl}_{4} \mathrm{O}_{7}$ (b) $\mathrm{NiAl}_{2} \mathrm{O}_{4}$ (c) $\mathrm{Ni}_{2} \mathrm{Al}_{2} \mathrm{O}_{5}$. 

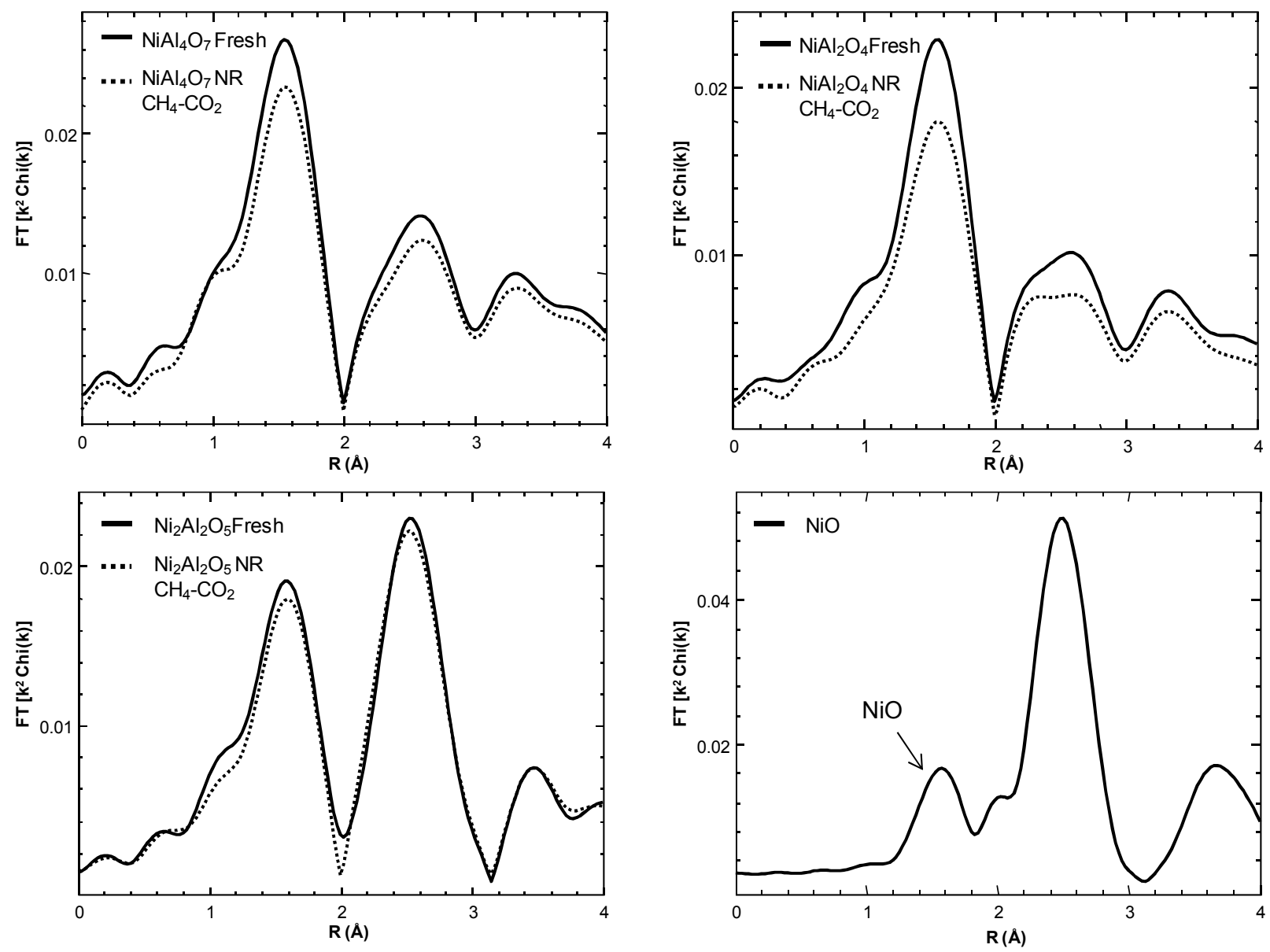

Figure S11 - Ni K-edge Fourier transform of the $\mathrm{k}^{2}$ weighted EXAFS of Fresh samples compared to samples under reaction conditions with the Ni K-edge Fourier transform of the $\mathrm{k}^{2}$ weighted EXAFS of $\mathrm{NiO}$ reference. 


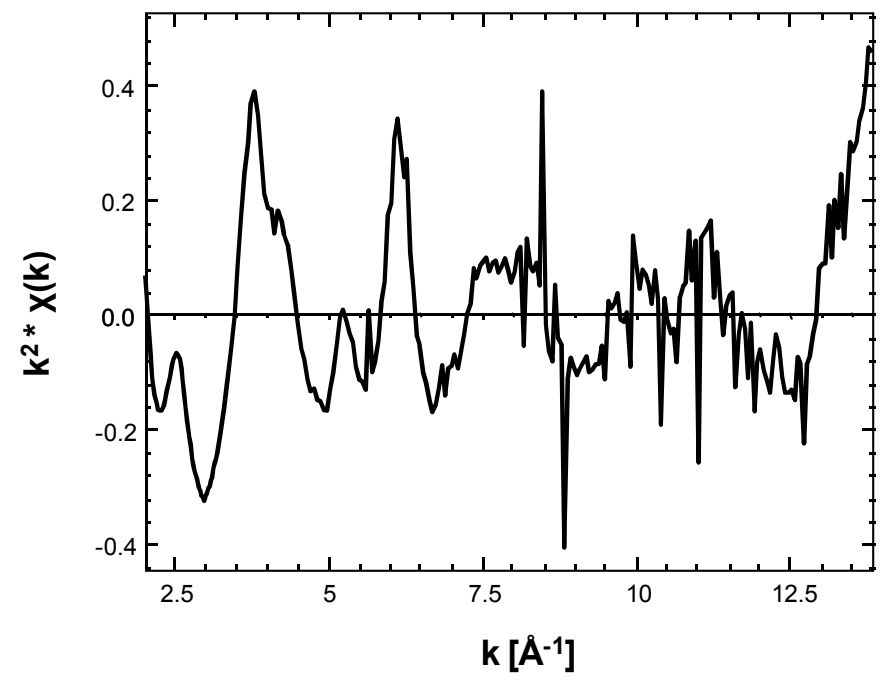

Figure $\mathrm{S} 12-\mathrm{K}^{2}$ weight of the difference spectra of $\mathrm{NiAl}_{2} \mathrm{O}_{4}$ fresh and after exposure to methane dry reforming.

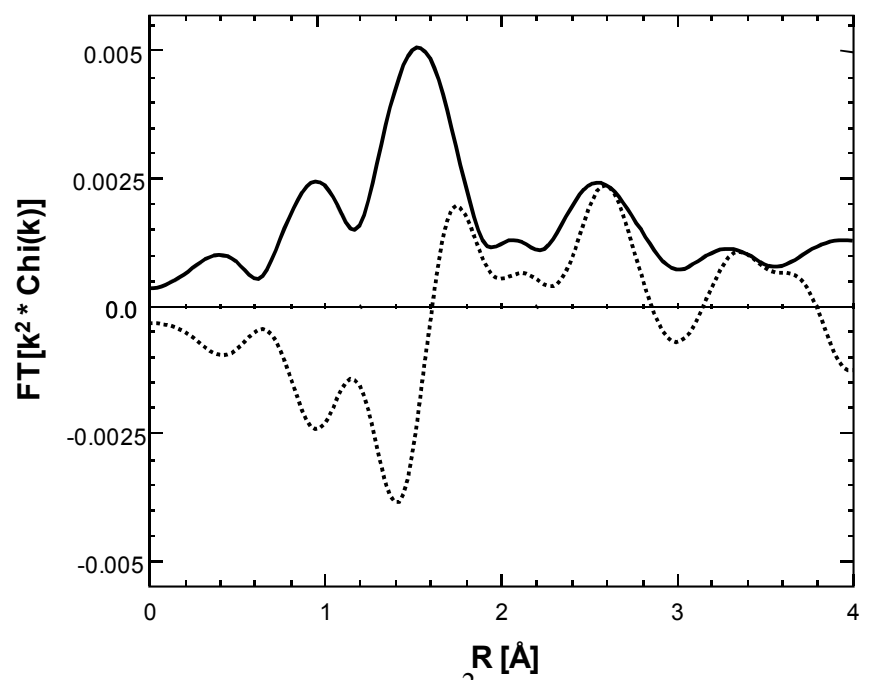

Figure S13 - Ni K-edge Fourier transform of the $\mathrm{k}^{2}$ weighted EXAFS of difference spectrum $\left(\Delta \mathrm{k}=2.5-10.5 \AA^{-1}\right.$; solid-magnitude FT and dotted-imaginary part FT). 


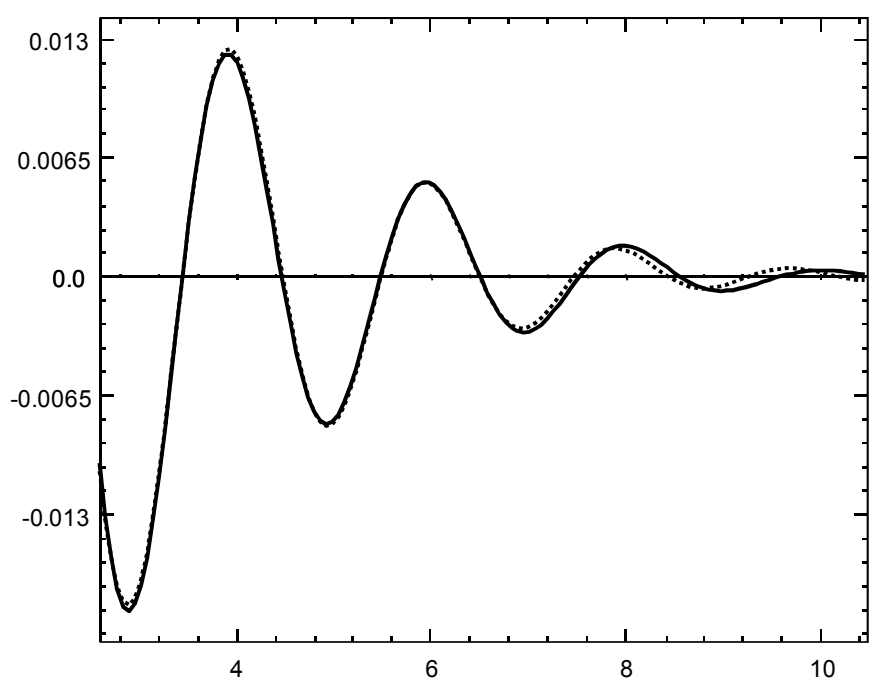

Figure S14 - Solid-reverse FT of EXAFS data over $\Delta \mathrm{k}=1.17-1.97 \AA^{-1}$ and dotted-EXAFS fit. Fit results: $\mathrm{N}=1.0, \mathrm{R}=2.08 \AA, \mathrm{DWF}=0, \mathrm{E}_{0}=-1.1$. 